\title{
Education Tea Ching Quality Engineering Improve the Quality of the New Normal Undergraduate Course Personnel Training
}

\author{
Bin Peng \\ Mianyang normal university \\ Mianyang normal school Peng Bin in sichuan province of China \\ Email:442392279 @qq.com
}

Keywords: new five engineering education of normal college teaching quality

\begin{abstract}
. to improve the teaching quality is the focus of higher education, for new normal undergraduate course colleges and universities, is the severe test. In this paper, from the subjects and course construction, improve the performance of management, improve the teachers' teaching evaluation mechanism, build good campus culture environment, thus put forward the implementation of school teaching work "five projects", to comprehensively improve the quality of the new normal undergraduate course school education goals.
\end{abstract}

\section{Introduction}

Higher education "quality project" is approved by the state council on the implementation of major of undergraduate course teaching reform project, is the "211 project", "985 project" and "national demonstrative higher vocational colleges and universities construction plan", directly to improve the quality of higher education and take important measures of profound significance. All this means that our country's higher education school-running mode, major changes will be to the quality strives for the survival, to the quality strives for the development, the full implementation of quality engineering, become the theme of survival and development of higher education. For new normal undergraduate course colleges and universities, it is the severe test.

It should be said that the new normal undergraduate course colleges and universities in order to improve the teaching quality of education made arduous efforts, has made remarkable achievement. But it is obvious that they also in the education teaching quality still exist many problems and shortcomings, such as in the aspect of education notion, traditional ideas are stubborn, need further update; In the construction of teachers team, although has always attached great importance to teachers' team construction, to ensure the teacher training, training funds, but due to the effect of area and hierarchical, senior talent introduction is difficult, the proportion of highly educated, high title teachers is not ideal; Worked as an intern in teaching equipments, experimental conditions, place, etc., while spending increased, but the construction still need increase; In the aspect of teaching reform, teachers' interest in the teaching reform is not high, difficult to calm down and think deeper problems in the teaching work, not to the teaching contents, teaching methods, curriculum system for serious study and discussion; In specialty construction aspects: professional structure is unreasonable, professional characteristics and advantage is not obvious, the mining and construction of traditional professional advantages are not enough; In the aspect of practice teaching: insufficient fund input, teachers' effort, students participate in practical teaching time, energy, inadequate investment, practical teaching management process is not standard, the experimental teaching content is old, and so on. 
Facing the wave of reform to improve the quality of teaching in the new period, the new normal undergraduate course colleges and universities should be more on the education teaching quality of ascension work under true kung fu.

The basic elements, integration of teaching process, vigorously promotes the professional disciplines and curriculum construction, and constantly deepen the reform of the education teaching

\section{Strengthen the construction of disciplines, optimize professional structure and layout}

New normal undergraduate course colleges and universities should be closely combined with the social development demand, on the basis of development, the principle of efficiency, coordination and heavy construction, adjust the professional, optimization of college professional, reasonable additional undergraduate programs, form a strong characteristic, advantage, structure more reasonable professional structure and layout, give full play to the talent advantage and scientific research advantages of the school, actively develop jucara vieira education, professional training to adapt to the local economic construction and social development needs a large number of excellent teachers to cultivate specialized personnel and other basic education.

\section{Promote the reform of teaching content and course system, constantly improve the level of teaching}

Actively explore the reform of teaching content and course system of the new train of thought, features and advantages in teacher education, on the basis of the new normal undergraduate course colleges and universities to optimize each setting, the construction of general education courses, discipline basic education courses, professional education courses, practice teaching courses and so on four big platform. On the quality course construction, the implementation of "qualification class high quality class - class quality" three-level curriculum construction system; Increasing funds guarantee, construction objectives and tasks with the accountability standards, to implement qualification admittance system, pays special attention to the qualification course, excellent course and the field construction, make the course quality has been further improved.

\section{Strengthen the practice teaching reform, improve students' comprehensive ability}

Around training goal request, construct a basic experiment, specialty experiment, practice, practice, innovation activities as the basic clue of practice teaching system; Update the practice teaching content, clear the proportion of comprehensive and designing experiment project and content, and according to project management; Through resource integration, system measures such as open laboratory; The school and department should vigorously promotes the construction of practice bases, forming the base number, practice and quality assurance system; Students' innovative education as a systems engineering issue, formulate rules for innovation, clear teaching, scientific research, association for science and technology, studies ministry responsibilities, from credit, performance and evaluation, funds and personnel, etc to strengthen students' innovation ability, improve students' comprehensive quality. At the same time, should further strengthen graduation thesis (design) work, improve the rules and regulations, all departments should be accordance with the requirements of the school, combining with the characteristics of professional and formulate specific implementation plan, make each link of graduation thesis (design) a well-planned, strict management, rule-based.

Second, in order to improve the management performance as the goal, strengthen the teaching management research, explore the effective education teaching management operation mechanism

Normal undergraduate course colleges and universities should put the quality of teaching as a new party chief leader and team assessment of school's important indicator, to strengthen the construction of teaching management organization and perfect led by competent authorities responsible for, the office of coordination, based on faculty and department of undergraduate teaching management system. To strengthen the teaching management, to ensure the normal order of job of teaching, to further strengthen the teaching management research, study on the basis of education science and management science, follow the rules of education teaching and the university student, 
the teaching management in final improve management performance; New normal undergraduate course colleges and universities should actively use the advanced management idea, steadily push forward reform of teaching management system, to explore further standardize education teaching management efficient operating mechanism; Scientific division has under the secondary management system, strengthen the teaching school (department) director (director), teaching secretary, educational administration and teaching management of information communication, achieve better service for teaching and teaching management service for the teachers, the function of serving for the students; Continue to strengthen the construction of the teaching routine, which is based on the teaching management system construction, establish a perfect school, school (department), teaching and research section of three-level quality system and implementation of a project, the assessment of teaching quality as an important index of every school party head.

Three, improve the teachers' teaching evaluation mechanism, comprehensively promote the construction of teachers team

Teach high [2007] no. 1, 2 file explicitly proposed "to strengthen the construction of undergraduate teaching team with high level of teachers", "intensify the building of teachers, teachers play important role to improve the quality of teaching". As a result, the new normal undergraduate course colleges and universities should be global and strategic perspective, improve the teachers' teaching evaluation mechanism, comprehensively promote the construction of teachers team. Further set up and implement the scientific outlook on development and talent, adhere to the people-oriented, is always the problem of talent as the development of the school reform and to grasp, formulate scientific development strategy planning and talent team construction planning, to the teachers team construction as the center, push forward the internal reform of the personnel system, build and perfect the personnel management incentive competition mechanism, intensify introduction and training of talents. First of all, to build a high teaching quality, reasonable structure of the teaching team, establish an effective team cooperation mechanism, promote the teaching contents, methods and research, promote the exchange of experience teaching and teaching methods, advancing teaching "in the old, middle-aged and young", the combination of carrying forward pass, help, belt, so to strengthen the training of young teachers. Second, to formulate effective measures, professor, associate professor must be for undergraduate teaching, to ensure the quality of undergraduate course teaching. At the same time, to play the role of mainstay, professor, associate professor in teaching reform, and actively encourage professor, associate professor in teaching reform, improving teaching content and teaching method, vigorously promote the heuristic teaching, constantly high level teaching reform results. Once again, to attach importance to part-time teacher team construction, and actively employ well-known experts and scholars at home and abroad and high level professional talents, undertake the task of teaching and lectures.

Fourth, to further strengthen the university spirit construction, teaching and learning, create a good campus culture environment

On the one hand, the new normal undergraduate course colleges and universities should adhere to party members and cadres fine style of work with excellent teaching teachers, from teachers' good teaching students the fine style of study, with excellent excellent school spirit and study style with school with excellent school spirit to promote the party member cadre's style of work, the working train of thought of wind teachers' and students' study. On the other hand, to adhere to the construction of study style in the party and overall responsibility of the university, studies ministry, office, and technology, the propaganda department, organization department, trade unions, various departments should work in landscape. Finally, the construction of ethics and professional ethics construction, strengthen the teachers' devotion to science and education, services, social sense of mission and social responsibility, form "ideals, wuxi, a teacher by worthy example, teaching, rigorous studious, advancing with The Times" good teaching style; By social demand as the guide, trains the student to have a clear purpose of study, stimulate students' intrinsic motivation, develop students' good self learning ability, practice ability, scientific innovation as the goal, to cultivate students with good ideological and moral qualities, scientific spirit and humanistic spirit and innovative spirit, forming 
good style of study in the school student, and the construction of "self-reliance, hard work, pragmatic innovation, the pursuit of excellence" school spirit.

Five, the implementation of the school teaching work "five projects", and comprehensively improve the quality of education

\section{The all-round innovation education construction project. New normal undergraduate course}

colleges and universities should improve college students' innovation ability as a systems engineering to conduct a comprehensive planning, do school leadership attaches great importance to, the related departments coordination, gradually build up students' innovation consciousness, cultivate the spirit of innovation, foster innovative thinking, the development of the long-term effective mechanism of innovation education of innovation ability and working mechanism. Strengthen the innovation education guidance work committee, the college students' independent innovation design center, college students' innovative association, set up a scientific research innovation fund, etc, for all the guidance and students' innovative work condition. Further perfecting the innovation measures for the implementation of credit, to carry out the innovation education research, the implementation of the student to participate in scientific research funds, personnel guarantee, ask scientific research achievements into classroom, into the teaching materials. Timely assembly innovation education, the innovation education in the implementation of the work to the school. Through the implementation of innovative education for construction project, and further form the school "to research and promote learning, in order to study with research, and research interaction" the innovation education new situation, improve the students' practical ability and innovative spirit.

\section{Continue to strengthen the construction of professional courses and teaching reform project.}

New normal undergraduate course colleges and universities should be based on "to the social demand as the guide, make contributions to local economic development," the thought of professional Settings, set flexible in senior professional direction, optimize the professional structure; Keep construction advantage, drive high quality courses, field elective courses, bilingual course construction, steadily push forward course construction.

\section{Improve the students' innovative practice ability construction project.}

In order to promote the innovation of practice teaching system reform, the new normal undergraduate course colleges and universities should further perfect the practice teaching system, the formation of innovation education. To integrate internal resources, form a resource sharing field for the purpose of the experiment teaching center and teaching demonstration center. At the same time, further consolidate and improve teachers' professional practice bases construction and non-normal professional off-campus practice bases. Actively encourage and support the teaching units and students to participate in provincial, national subject competitions, to strengthen the innovation practice ability, strive to achieve excellent results in provincial and national competitions.

\section{Strengthen the routine teaching management and teaching quality of construction engineering.}

New normal undergraduate course colleges and universities should continue to strengthen the construction of the teaching routine, which is based on construction of teaching management system, perfect the teaching links of quality standards, set up a school, the school (department), teaching and research section 3 quality system. First of all, to implement "to a teacher demonstration class lectures, in each teaching unit 'classroom teaching everyone pass' activities as the key point, listen to the teacher teaching supervisor targeted as the main monitoring means" the teaching quality of engineering. Secondly, the professor, associate professor class as a basic system for undergraduate students, should actively organize young teachers teaching training, please participate regularly teacher lectures on teaching contents, means and methods, through holding young teachers teaching skills contest, multimedia courseware competition, improve the level of teachers' classroom teaching in an all-round way. 


\section{The implementation of college English teaching reform and the construction project with the computer.}

To improve the students' English and computer level, normal undergraduate course colleges and universities should set up new "college English teaching steering committee" "university computer foundation teaching steering committee", the relevant functional departments to further perfect the institutions and the system construction, to carry out the target responsibility system, carry out research and outside school training, set up a special educational reform project, to promote team building and the work carries out.

We believe that through the implementation of education teaching quality engineering, and comprehensively improve the quality of personnel training, the new normal undergraduate course colleges and universities must be implemented by the pure knowledge talent cultivation to cultivating high comprehensive quality and innovation ability of inter-disciplinary talent direction, so as to adapt to the trend of the development of higher education, actively serve social and economic development.

\section{References:}

[1] "about to strengthen job of undergraduate course teaching of colleges and universities, and several opinions to improve the quality of teaching. Teaching high [2001] no. 4.

[2] "on the implementation of institutions of higher learning the opinions of the undergraduate teaching quality and teaching reform project". Teach high [2007] no. 1.

[3] "on further deepening the reform of undergraduate teaching, improving teaching quality of several opinions. Teach high [2007] no. 2.

[4] xiao-chun Chen. The newly built local undergraduate colleges and universities personnel training quality series.the [J]. Journal of leshan teachers college, 2006, (11). 